\section{(- OPEN ACCESS}

\title{
Exposure to passive smoking and rheumatoid arthritis risk: results from the Swedish EIRA study
}

\author{
Anna Karin Hedström, ${ }^{1,2}$ Lars Klareskog, ${ }^{3}$ Lars Alfredsson ${ }^{2,4}$
}

\begin{abstract}
Handling editor Josef $\mathrm{S}$ Smolen

- Additional material is published online only. To view please visit the journal online (http://dx.doi.org/10.1136/ annrheumdis-2018-212973).
\end{abstract}

${ }^{1}$ Department of Clinical Neuroscience, Karolinska University Hospital, Stockholm, Sweden

${ }^{2}$ Institute of Environmental Medicine, Karolinska Institutet, Stockholm, Sweden

${ }^{3}$ Rheumatology Unit, Department of Medicine, Karolinska Institutet, Stockholm, Sweden

${ }^{4}$ Centre for Occupational and Environmental Medicine, Stockholm County Council, Stockholm, Sweden

Correspondence to Dr Anna Karin Hedström, Institute of Environmental Medicine, Karolinska Institutet Stockholm 171 76, Sweden: anna.hedstrom@ki.se

Received 8 January 2018 Revised 12 March 2018

Accepted 22 March 2018 Published Online First 3 May 2018

\section{Check for updates}

To cite: Hedström AK, Klareskog L, Alfredsson L. Ann Rheum Dis

2018;77:970-972.

\section{ABSTRACT}

Introduction Smoking has consistently been associated with increased risk of developing rheumatoid arthritis (RA). The aim of this study was to estimate the influence of passive smoking on the risk of developing anti-cyclic citrullinated peptide antibodies (ACPA)-positive and ACPA-negative RA.

Methods A population-based case-control study using incident cases of RA was performed in Sweden, and the study population in this report was restricted to include never-smokers (589 cases, 1764 controls). The incidence of RA among never-smokers who had been exposed to passive smoking was compared with that of neversmokers who had never been exposed, by calculating the OR with a $95 \% \mathrm{Cl}$ employing logistic regression.

Results No association was observed between exposure to passive smoking and RA risk (OR 1.0, $95 \% \mathrm{Cl} 0.8$ to 1.2 for ACPA-positive RA, and OR 0.9, $95 \% \mathrm{Cl} 0.7$ to 1.2 , for ACPA-negative RA). No suggestion of a trend between duration of passive smoking and RA risk was observed.

Discussions No association was observed between exposure to passive smoking and RA risk, which may be explained by a threshold below which no association between smoke exposure and RA occurs.

\section{INTRODUCTION}

Rheumatoid arthritis (RA) is systemic inflammatory disease characterised by progressive joint destruction and autoantibody formation. Based on serological features, RA can be divided into anti-cyclic citrullinated peptide antibodies (ACPA)-positive and ACPA-negative subsets. ${ }^{1}$ Disease susceptibility is determined by a complex interplay between genetic and environmental factors, and both retrospective and prospective studies have demonstrated that smoking is one of the major environmental factors in RA development. ${ }^{2-5}$ Smoking has been observed to induce citrullination of peptide antigens in the lungs ${ }^{6}$ and has been reported to be an important factor for the development of RA in the ACPA-positive subset. ${ }^{7}$

No studies have been performed investigating the effect of environmental tobacco smoke on RA risk. However, maternal smoking during pregnancy has been reported to increase the risk of inflammatory polyarthropathies and juvenile RA in female offspring. ${ }^{8}$ The effect of environmental tobacco smoke on disease activity in RA has been investigated in a multicentre longitudinal observational study of patients with RA, and no impact of passive smoking on disease activity was observed among never-smoking patients with RA. ${ }^{9}$ Using a large Swedish population-based case-control study we thus aimed to examine whether exposure to passive smoking influences the risk of developing ACPA-positive and ACPA-negative RA.

\section{METHODS}

\section{Study design and study subjects}

This report was based on data from the ongoing project Epidemiological Investigation of Rheumatoid Arthritis (EIRA) which is a population-based case-control study comprising the population aged 18-70 years in the middle and southern parts of Sweden. All hospital-based and most privately run rheumatology units participated in recruiting incident cases to the study. All cases fulfilled the American College of Rheumatology 1987 criteria. For each case, two controls were randomly selected from the national population register, matched by age, gender and residential area. A more detailed description of the study design can be found elsewhere. $^{10}$

During the study period October 2005 to September 2014, completed questionnaires were obtained from 1652 cases and 3553 controls, the response proportion being $92 \%$ for the cases and $75 \%$ for the controls.

\section{Anti-cyclic citrullinated peptide antibodies}

ACPA status among cases was analysed using Immunoscan-RA Mark2 ELISA test (anti-CCP2 test). An antibody level exceeding $25 \mathrm{AU} / \mathrm{mL}$ was regarded as ACPA positivity.

\section{Data collection}

Information regarding lifestyle factors and different exposures was collected using a standardised questionnaire. Information on smoking was obtained by asking about current and previous smoking habits, and information on exposure to passive smoking was obtained by asking if the subject had been daily exposed to passive smoking at home or at work, and if so, during what period or periods in life.

For each case, the time of the initial appearance of RA symptoms was used as an estimate of the disease onset, and the year in which this occurred was defined as the index year. The corresponding controls were given the same index year. Information regarding smoking and exposure to passive smoking was considered prior to or during the index year in the cases and during the same period of time in the corresponding controls.

All ever-smokers were excluded (1063 cases and 1789 controls). Never-smokers who reported exposure to passive smoking prior to index were 
defined as exposed whereas those who reported that they had never been exposed to passive smoking were defined as never exposed. Exposed subjects were also divided into groups based on whether the exposure occurred within 10 years prior to index or earlier in life. In order to analyse the influence of duration of exposure to passive smoking on the risk of developing the disease, we categorised the exposed subjects into groups based on the duration of exposure prior to index.

\section{Statistical analysis}

Among never-smokers, subjects exposed to passive smoking were compared with those that reported never having been exposed to passive smoking with regard to occurrence of RA, by calculating ORs with 95\% CIs employing logistic regression. Trend test for a dose-response relationship regarding duration of passive smoking and risk of both subsets of RA was performed by using a continuous variable for duration of passive smoking (years) in a logistic regression model.

Both matched and unmatched analyses were carried out. The results from the unmatched analyses were in close agreement with those from the matched analyses but had a higher degree of precision due to a substantial loss of cases and controls in the matched analyses.

All analyses were adjusted for age, gender, residential area and ancestry. Assessment of ancestry was based on whether the subject was born in Scandinavia or not, and whether either of the subject's parents had immigrated to Scandinavia. A subject who was born in Scandinavia, whose parents had not immigrated, was classified as Scandinavian. Adjustments were also made for educational level (university degree or not), alcohol consumption (number of drinks per week at study inclusion) and body mass index at inclusion in the study (more or less than $25 \mathrm{~kg}$ / $\mathrm{m}^{2}$ ). However, these factors had a minor influence on the results and were not retained in the final analyses. All analyses were conducted using SAS V.9.2.

\section{RESULTS}

Our analyses of passive smoking and RA risk among neversmokers included 589 cases and 1764 controls. Overall, the proportion that had been exposed to passive smoking prior to the index year was 47\% among ACPA-positive cases, $48 \%$ among ACPA-negative cases and 50\% among controls. Characteristics of cases and controls are presented in table 1.

No association was observed between exposure to passive smoking and risk of ACPA-positive or ACPA-negative RA, regardless if the exposure took place within 10 years prior to index or earlier in life. Compared with those who had never been exposed to passive smoking, the OR was 1.0 (95\% CI

Table 1 Characteristics of cases and controls

\begin{tabular}{lccr}
\hline & $\begin{array}{l}\text { ACPA- } \\
\text { positive } \\
\text { cases }\end{array}$ & $\begin{array}{l}\text { ACPA- } \\
\text { negative } \\
\text { cases }\end{array}$ & Controls \\
\hline Exposed to passive smoking, $\mathrm{n}(\%)$ & $180(47)$ & $98(48)$ & $876(50)$ \\
\hline Women, $\mathrm{n}(\%)$ & $301(78)$ & $137(67)$ & $1293(73)$ \\
\hline Men, $\mathrm{n}(\%)$ & $84(22)$ & $67(33)$ & $471(27)$ \\
\hline Scandinavian, $\mathrm{n}(\%)$ & $333(86)$ & $185(91)$ & $1533(87)$ \\
\hline Mean age at disease onset (SD) & $52.8(16.0)$ & $47.8(15.3)$ & \\
\hline $\begin{array}{l}\text { Disease duration since first symptom } \\
\text { (SD) }\end{array}$ & $0.8(1.1)$ & $0.9(1.2)$ & \\
\hline Total, $\mathrm{n}$ & 385 & 204 & 1764 \\
\hline ACPA, a & & & \\
\hline
\end{tabular}

ACPA, anti-cyclic citrullinated peptide antibodies.
Table 2 OR with $95 \% \mathrm{Cl}$ of developing rheumatoid arthritis (RA) for subjects exposed to passive smoking compared with those who have never been exposed

\begin{tabular}{|c|c|c|c|c|}
\hline \multirow{2}{*}{$\begin{array}{l}\text { Exposure to } \\
\text { passive smoking }\end{array}$} & \multicolumn{2}{|c|}{ ACPA-positive RA } & \multicolumn{2}{|c|}{ ACPA-negative RA } \\
\hline & $\mathrm{ca} / \mathrm{co}$ & OR $(95 \% \mathrm{Cl})^{*}$ & $\mathrm{ca} / \mathrm{co}$ & OR $(95 \% \mathrm{Cl})^{*}$ \\
\hline Never & $205 / 888$ & 1.0 (reference) & $106 / 888$ & 1.0 (reference) \\
\hline Ever & $180 / 876$ & $1.0(0.8$ to 1.2$)$ & $98 / 876$ & 0.9 (0.7 to 1.2$)$ \\
\hline $\begin{array}{l}\text { Within } 10 \text { years } \\
\text { prior to index }\end{array}$ & $45 / 170$ & 1.1 (0.8 to 1.7$)$ & $15 / 170$ & 0.7 (0.4 to 1.3$)$ \\
\hline $\begin{array}{l}\text { Before } 10 \text { years } \\
\text { prior to index }\end{array}$ & $135 / 706$ & $0.9(0.7$ to 1.2$)$ & $83 / 706$ & $1.0(0.7$ to 1.3$)$ \\
\hline
\end{tabular}

All subjects were never-smokers.

${ }^{*}$ Adjusted for age, gender, residential area and ancestry.

ACPA, anti-cyclic citrullinated peptide antibodies; ca/co, number of exposed cases and controls.

0.7 to 1.2 ) for ACPA-positive RA and 0.9 (95\% CI 0.7 to 1.2 ) for ACPA-negative RA among those ever exposed to passive smoking (table 2). The results from the matched analysis are presented in online supplementary table 1 . There were no significant age-related or gender-related differences. There was no suggestion of a trend between duration of passive smoking and RA risk. Long-term exposure to passive smoking for 20 years or longer was not significantly associated with increased disease susceptibility (table 3 ).

\section{DISCUSSION}

According to our observations among never-smokers, exposure to passive smoking did not increase the risk of ACPA-positive or ACPA-negative RA. The present result of a lack of association between passive smoking and risk for RA may be due to the previously described threshold for exposure to smoke, where no association between risk for RA and active smoking was seen when the accumulated amount of smoking was low enough. ${ }^{10}$ However, we only had information on duration but not intensity of exposure to passive smoking and we were therefore unable to calculate the cumulative dose of passively inhaled smoke in order to study a dose-response correlation. ${ }^{11}$ Although exposure to passive smoking does not seem to be a risk factor for RA, we cannot rule out that extensive exposure to passive smoking could affect disease risk.

Our study was designed as a case-control study with incident cases, and information regarding smoking habits and exposure to passive smoking was collected retrospectively. Recall bias was minimised by using incident cases of RA. The mean duration

Table 3 OR with $95 \% \mathrm{Cl}$ of developing rheumatoid arthritis (RA) for subjects exposed to passive smoking compared with those who have never been exposed, by duration of exposure

\begin{tabular}{|c|c|c|c|c|}
\hline \multirow{2}{*}{$\begin{array}{l}\text { Duration of } \\
\text { exposure to passive } \\
\text { smoking (years) }\end{array}$} & \multicolumn{2}{|c|}{ ACPA-positive RA } & \multicolumn{2}{|c|}{ ACPA-negative RA } \\
\hline & $\mathrm{ca} / \mathrm{co}$ & OR $(95 \% \mathrm{Cl})^{*}$ & $\mathrm{ca} / \mathrm{co}$ & OR $(95 \% \mathrm{Cl})^{*}$ \\
\hline 0 & $205 / 897$ & 1.0 (reference) & $108 / 897$ & 1.0 (reference) \\
\hline $1-9$ & $52 / 221$ & $1.0(0.7-1.5)$ & $18 / 221$ & $0.7(0.4-1.2)$ \\
\hline 10-19 & $66 / 319$ & $1.0(0.7-1.3)$ & $33 / 319$ & $0.9(0.6-1.3)$ \\
\hline $20-$ & $616 / 325$ & $0.9(0.7-1.3)$ & $45 / 325$ & $1.1(0.7-1.6)$ \\
\hline$P$ values for trend & & 0.8 & & 0.8 \\
\hline
\end{tabular}

All subjects were never-smokers.

${ }^{*}$ Adjusted for age, gender, residential area and ancestry.

ACPA, anti-cyclic citrullinated peptide antibodies; $\mathrm{ca} / \mathrm{co}$, number of exposed cases and control. 
from the disease onset to inclusion in the study was $<1$ year in both subgroups. We took great effort to obtain information on lifestyle factors and environmental exposures in an identical way for the cases and the controls. Furthermore, the questionnaire contained a wide range of questions regarding many potential environmental risk factors and no section in the questionnaire was given prime focus.

A potential selection bias may arise when recruiting cases and controls. The proportion of respondents with regard to participation in EIRA was $92 \%$ for cases and $75 \%$ for controls. Since the structure of the Swedish public healthcare system provides equal access to medical services for all Swedish citizens, almost all cases of RA are referred to public rheumatology units and it is not likely that the few unidentified cases would cause a substantial bias in our calculations. Selection bias among controls is likely to be modest since the prevalence of smoking among controls, seen as an indicator of lifestyle, was in line with that of the general population at equivalent ages. ${ }^{12}$

When observing no association between exposure and disease, as in our study, it is of interest to know what strengths of association the study had a reasonably power to detect. Comparing ever exposed to passive smoking to never exposed, our study had the power $(\geq 80)$ to identify an OR of 1.33 for ACPA-positive RA and 1.45 for ACPA-negative RA.

In summary, in this population-based case-control study of RA, no association was observed between exposure to passive smoking and risk of ACPA-positive or ACPA-negative RA among never-smokers. Our finding may be explained by a threshold below which no association between smoke exposure and RA occurs.

Contributors Conception and design of the study, and acquisition of data: LA and LK. Analysis of data and drafting of the manuscript and tables: AKH. All authors revised the manuscript for important intellectual content.

Funding The EIRA study was supported by grants from the Swedish Medical Research Council, the Swedish Council for Health, Working life and Welfare, King Gustaf V:s 80-year foundation, the Swedish Rheumatism Foundation, Stockholm County Council, the insurance company AFA and the IMU-supported BeTheCure projects.

Competing interests None declared.

Patient consent Not required.
Ethics approval The ethics committee of the Karolinska Institutet.

Provenance and peer review Not commissioned; externally peer reviewed.

Open access This is an Open Access article distributed in accordance with the Creative Commons Attribution Non Commercial (CC BY-NC 4.0) license, which permits others to distribute, remix, adapt, build upon this work non-commercially, and license their derivative works on different terms, provided the original work is properly cited and the use is non-commercial. See: http://creativecommons.org/ licenses/by-nc/4.0/

(C) Article author(s) (or their employer(s) unless otherwise stated in the text of the article) 2018. All rights reserved. No commercial use is permitted unless otherwise expressly granted.

\section{REFERENCES}

1 Aletaha D, Neogi T, Silman AJ, et al. 2010 rheumatoid arthritis classification criteria: an American College of Rheumatology/European League Against Rheumatism collaborative initiative. Ann Rheum Dis 2010:69:1580-8.

2 Padyukov L, Silva C, Stolt P, et al. A gene-environment interaction between smoking and shared epitope genes in HLA-DR provides a high risk of seropositive rheumatoid arthritis. Arthritis Rheum 2004;50:3085-92.

3 Costenbader KH, Feskanich D, Mandl LA, et al. Smoking intensity, duration, and cessation, and the risk of rheumatoid arthritis in women. Am J Med 2006;119:503. e1-503.e9.

4 Sugiyama D, Nishimura K, Tamaki K, et al. Impact of smoking as a risk factor for developing rheumatoid arthritis: a meta-analysis of observational studies. Ann Rheum Dis 2010;69:70-81.

5 Di Giuseppe D, Discacciati A, Orsini N, et al. Cigarette smoking and risk of rheumatoid arthritis: a dose-response meta-analysis. Arthritis Res Ther 2014;16:R61.

6 Makrygiannakis D, Hermansson M, Ulfgren AK, et al. Smoking increases peptidylarginine deiminase 2 enzyme expression in human lungs and increases citrullination in BAL cells. Ann Rheum Dis 2008;67:1488-92.

7 Klareskog L, Stolt P, Lundberg K, et al. A new model for an etiology of rheumatoid arthritis: smoking may trigger HLA-DR (shared epitope)-restricted immune reactions to autoantigens modified by citrullination. Arthritis Rheum 2006;54:38-46.

8 Jaakkola JJ, Gissler M. Maternal smoking in pregnancy as a determinant of rheumatoid arthritis and other inflammatory polyarthropathies during the first 7 years of life. Int J Epidemio/ 2005;34:664-71.

9 Söderlin MK, Andersson M, Bergman S. BARFOT study group. Second-hand exposure to tobacco smoke and its effect on disease activity in Swedish rheumatoid arthritis patients. Data from BARFOT, a multicenter study of RA. Clin Exp Rheumatol 2013:31:122-4

10 Hedström AK, Stawiarz L, Klareskog L, et al. Smoking and susceptibility to rheumatoid arthritis in a Swedish population-based case-control study. Eur J Epidemiol 2018. Epub ahead of print.

11 Stolt P, Bengtsson C, Nordmark B, et al. Quantification of the influence of cigarette smoking on rheumatoid arthritis: results from a population based case-control study, using incident cases. Ann Rheum Dis 2003;62:835-41.

12 Internet-based information. http://www.scb.se (accessed 5 Nov 2017). 